\title{
Organic electrolytes for graphene-based supercapacitor: Liquid, gel or solid
}

\author{
Evgeniya Kovalska*, Coskun Kocabas \\ Department of Physics, Bilkent University, 06800 Ankara, Turkey
}

\section{A R T I C L E I N F O}

\section{Article history:}

Received 26 April 2016

Accepted 27 April 2016

Available online 6 May 2016

\section{Keywords:}

Graphene-based supercapacitor

Organic electrolyte

Electrical and electro-optical features

Optical modulator

\begin{abstract}
A B S T R A C T
The electrolyte is an important and decisive factor in battery, capacitor and supercapacitor fabrication. Here we report how electrolyte's provenance and structure effect on the electro-optical properties of the graphene-based supercapacitor. The three organic electrolytes were synthesized: liquid electrolyte, which on the basis of propylene carbonate (PC), gel electrolyte - polyvinyl alcohol (PVA) and solid electrolyte - polyvinylidene fluoride (PVDF). As an application, we demonstrate an optical modulator using supercapacitor structure built by graphene electrodes and prepared electrolytes. All organic electrolyte-based supercapacitors potentiate optical modulation of graphene electrodes over a broad range of wavelengths, under ambient conditions. We reveal higher capacitance $\left(78 \mu \mathrm{F} / \mathrm{cm}^{2}\right)$ for a supercapacitor with gel electrolyte during various bias voltages. We represent the increasing of light transmission at 3 times using solid electrolyte, in comparison with liquid and gel electrolytes and illustrate the supercapacitor possibility with gel electrolyte to operate under negative voltage. Consequently, we suggest applying of solid electrolyte as a more appropriate electrolyte for fabrication of graphene-based supercapacitor. We anticipate that using of solid electrolyte allows us to get desired electro-optical properties, minimize the size of the device and vary it shape.
\end{abstract}

(c) 2016 Elsevier Ltd. All rights reserved.

\section{Introduction}

The supercapacitor history has more than a dozen years, but technique demand of such devices still makes scientists look for ways to reduce the cost of their development and production [1]. Supercapacitor, which also well-known as ultra- or electric doublelayer capacitor stores energy through reversible ion adsorption onto active materials with high specific surface area [2]: activated carbon [3], graphene [4,5], carbon aerogel [6,7], or carbon nanotubes $[8,9]$. Except carbon materials, researchers use electroactive oxide or hydroxide films of transition metals $\left(\mathrm{MnO}_{2}\right.$ [10], $\mathrm{RuO}_{2}$ [11], $\mathrm{NiO}$ [12], $\mathrm{MoO}_{3}$ [13]) and conducting polymers (polypyrrole [14], polyaniline [15], and polythiophene [16] etc.). The cyclic stability and performance of supercapacitor depend on properties of electrolyte as well. Electrolytes - these are liquid, gel or solid systems which must have the high concentration of mobile ions, low resistance, low concentration of electrically active impurities, and be chemically stable $[17,18]$. For the purpose to get quality supercapacitor we have to find the optimal combination of electrodes with electrolyte.

\footnotetext{
* Corresponding author.

E-mail address: ikovalska@bilkent.edu.tr (E. Kovalska).
}

Liquid electrolytes which consist of water and organic chains have ionic conductivity up to $1 \mathrm{~S} / \mathrm{cm}$, high dielectric constant [18], and give higher specific capacitance of active materials than the organic-based electrolyte. The cell voltage of supercapacitors based on aqueous electrolyte is lower (1 V) [19] than organic electrolyte $(2.5 \mathrm{~V})[20]$. Thus, we were able to obtain significantly better results with non-aqueous [21], biological substances [22] or polymer solid electrolyte [23]. To avoid the shape restrictions, leakage or drying of electrolyte (that inherent of liquids) we can use gel electrolyte. It has fast charging/discharging and high power density as well [24]. Currently, the major polymers for gel electrolyte preparation are polyethylene oxide [25], polyacrylonitrile [26], polymethyl methacrylate [27] polyvinylidene fluoride [28] etc. Relatively new electrolyte for supercapacitor design is solid electrolyte [29,30]. This material offers many advantages over the liquids and gels: conduction of electricity, due to the ion movement through voids or defects, in own crystal lattice; leakage resistance, due to dispersion and fixation, into a polymer matrix; dual functionalization as separator and electrolyte. Solid electrolytes implement in the design of flexible and nonflexible supercapacitors and show excellent electrochemical performance $[9,31,32]$.

In any case, properties of electrolyte and its structure determine applied aspects of the supercapacitor. Thus, we report syntheses of liquid, gel and solid organic electrolytes and 
electro-optical/electro-absorption modulations of light using these electrolytes for graphene-based supercapacitor.

\section{Experimental}

\subsection{Synthesis of monolayer graphene}

Monolayer graphene was synthesized by CVD-method (chemical vapor deposition) using as a catalyst $25 \mu \mathrm{m}$ thick copper foil (Alfa Aesar item \#13382). The copper pieces were loaded into a quartz chamber and heated to the $1035^{\circ} \mathrm{C}$ under vacuum in $80 \mathrm{sscm}$ $\mathrm{H}_{2}$ and annealed $30 \mathrm{~min}$. After annealing a $40 \mathrm{sscm} \mathrm{CH}_{4}$ flow (source of carbon) was added to the $\mathrm{H}_{2}$ flow. Afterward, 30 min graphene growth was carried out cooling down with $\mathrm{H}_{2}$ flowing until the temperature was below $100^{\circ} \mathrm{C}$. Graphene on copper was taken out of the CVD-reactor when the temperature reached $50-60^{\circ} \mathrm{C}$.

\subsection{Transfer of monolayer graphene using S1813}

A photoresist S1813 (Shipley Company) supported transfer method was utilized to transfer graphene (with the area around $1 \times 2 \mathrm{~cm}$ ) to the polish quartz wafers for supercapacitor fabrication. The etching processes were performed by $\mathrm{FeCl}_{3}$ for $\mathrm{Cu}$-foil and using acetone for removing of photoresist.

\subsection{Fabrication graphene-based supercapacitor}

Supercapacitor cell was formed using two covered by graphene glass wafers. Afterward, the vastness between two electrodes was filled with an electrolyte according to its type. We have used the pipette for liquid and gel electrolytes and tweezers for a thin transparent film of solid one.

\subsection{Preparation of the electrolytes}

Different types of electrolyte systems which based on organic chemicals were prepared.

Liquid electrolyte with active $\mathrm{Li}^{+}$-ions were obtained using a solvent propylene carbonate ( $\mathrm{PC}-\mathrm{C}_{4} \mathrm{H}_{6} \mathrm{O}_{3}, 99.7 \%$, Sigma-Aldrich) and the source of positive ions - lithium bis (oxalate) borate (LiBOB $\mathrm{LiB}\left(\mathrm{C}_{2} \mathrm{O}_{4}\right)_{2}$, powder of crystals, Sigma-Aldrich). The mixture was stirred around 2. A transparent and diluted milk color electrolyte with a concentration of $\mathrm{Li}^{+}$-ions $10 \mathrm{wt} . \%$. were finally obtained.

LiBOB was used for gel electrolyte preparation as well. Polyvinyl alcohol (PVA - $\left(\mathrm{CH}_{2} \mathrm{CHOH}\right)_{n}$, Sigma-Aldrich) with an average molecular weight of 20,000 was dissolved in $10 \% \mathrm{Li}^{+}$-ions aqueous solution. Glycerin $\left(\mathrm{C}_{3} \mathrm{H}_{8} \mathrm{O}_{3}\right.$, Birpa, Ankara) was added as a stabilizer. Lastly, we have got good pellucid gel electrolyte.

A solid electrolyte was obtained using polyvinylidene fluoride, with nominal $M_{n}=130,000 \mathrm{~g} / \mathrm{mol}, M_{w}=400,000 \mathrm{~g} / \mathrm{mol}$, melting point $140-145^{\circ} \mathrm{C}$ (PVDF) - molecular structure is $-\left[\mathrm{CH}_{2}-\mathrm{CF}_{2}\right]_{n}-\left[\mathrm{CF}_{2}-\mathrm{CF}\left(\mathrm{CF}_{3}\right)\right]_{m}-$, Sigma-Aldrich. The polymer solution was prepared by dissolving $10 \mathrm{wt} . \%$ of PVDF in acetone at $70^{\circ} \mathrm{C}$ under magnetic stirring for at least $30 \mathrm{~min}$ until a clear homogeneous solution was obtained. The ionic liquid in the ratio 1:4 (polymer:ionic liquid, respectively) was added to the polymer solution under magnetic stirring and they dissolved completely in a few minutes. The following ionic liquid which supplied by Sigma-Aldrich were used: 1-butyl-3-methylimidazolium hexafluorophosphate $-\mathrm{C}_{8} \mathrm{H}_{15} \mathrm{~F}_{6} \mathrm{~N}_{2} \mathrm{P}$. The films were prepared by solution casting of the polymer/ionic liquid mixture in acetone on a Petri dish and by subsequent solvent evaporation at room temperature for $24 \mathrm{~h}$. Further, the films were dried at $70^{\circ} \mathrm{C}$ for $4 \mathrm{~h}$ to guarantee complete removal of the volatile solvent.

\subsection{Electrical measurements}

The capacitance and resistance of the devices were characterized using an HP 4284 A precision LCR meter as a function of bias voltage. The voltage bias was applied using a Keithly 2400 Source Measure Unit.

\subsection{Optical transmittance measurements}

Changing of the transmission versus the wavelength (in the visible and near-infrared) for various bias voltages was investigated using a Bruker Vertex 70V FTIR spectrometer (Jobin Yvon Raman microscope system, $50 \times$ microscope objective, the wavelength was $532 \mathrm{~nm}$, Si photodiode). We worked in the wavelength range between 500 and $1100 \mathrm{~nm}$. The graphene-based supercapacitor was biased using Keithley 2400 source measure unit the transmittance measurements.

\section{Result and discussion}

The choice of graphene as an electrode caused by its high absorption coefficient in broad spectral range, excellent transport properties and gate-tunable carrier density. The ability to produce high-quality single-layer graphene [33,34], and transfer it onto substrate makes practical application of graphene for optoelectronic devices. Nowadays graphene integrated with silicon photonics is especially interesting [35] and would be of use for optical communication applications [36]. For this purpose graphene-on-graphene optical modulator with parallel plate geometry was described $[37,38]$. However, we would like to consider broadband optical modulator which consists of two graphene electrodes on the glass/PVC wafers and electrolyte between them. The devices have simple parallel plate geometry and based on the supercapacitor structure.

\subsection{Graphene-based supercapacitor}

We present graphene-based supercapacitor which was fabricated using glass wafers, covered with single-layer graphene (Fig. 1), and liquid or gel electrolytes (Fig. 2a); flexible supercapacitor, where is solid electrolyte between two graphene electrodes (Fig. 2b).

Graphene-based device works on the principle of a typical supercapacitor (Fig. 2c), which stores electric charge directly across the interface. The mechanism of surface charge generation can be enumerated as surface dissociation and ion adsorption from the electrolyte solution. The capacitance arises from an electrochemical double layer and its thickness depends on the concentration of the electrolyte and size of active ions.

\subsection{Electrolytes for graphene-based supercapacitor}

We tested electrolytes of various composition and state: the first electrolyte is liquid, the following five - gels and remaining - are solids (Table 1 ). To avoid leakage of electrolyte and shape limitation of the device we use polymeric matrixes: polyvinyl alcohol (PVA) and polyvinylidene fluoride (PVDF); as a source of ions we use lithium salt or inorganic acids. Herein, we distinguish and compare three electrolytes, which in our opinion are most suitable for supercapacitors as an optical modulators [39].

\subsection{Liquid electrolyte $-P C / L i B O B$}

We prepared the solution of lithium bis (oxalate) borate in propylene carbonate (PC/LiBOB) [40]. The choice fell on LiBOB because its advantages such as stability at elevated temperature 
(a)

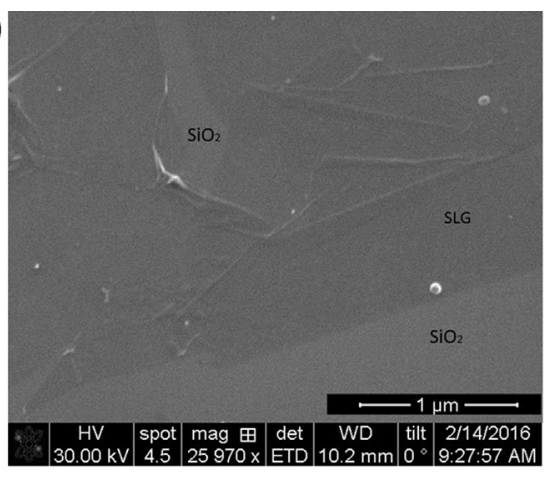

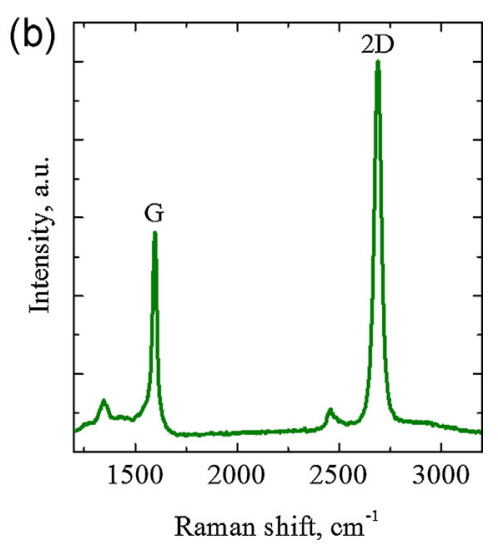

Fig. 1. SEM image (a) and typical Raman spectra (b) of single layer graphene film coated on $\mathrm{Si} / \mathrm{SiO}_{2}$ substrate.

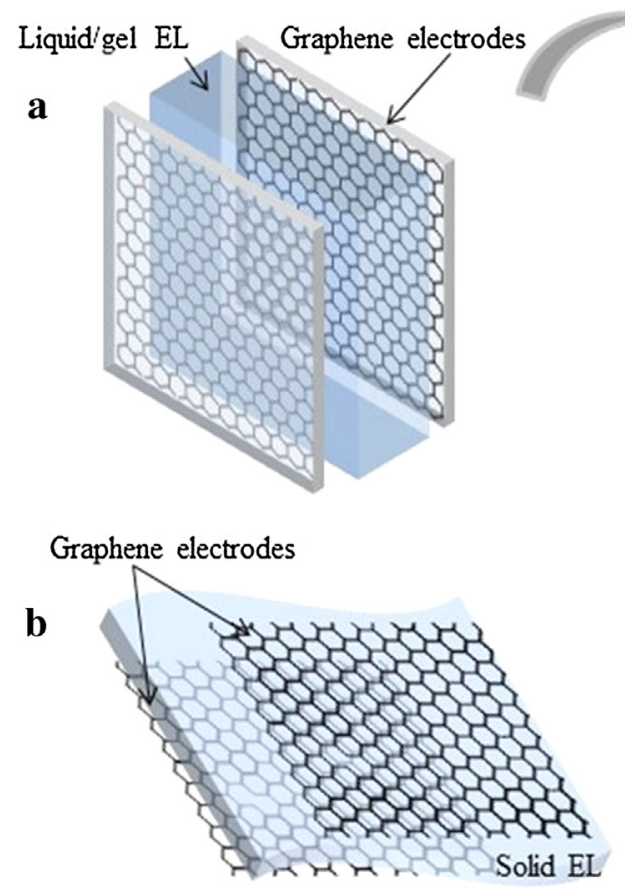

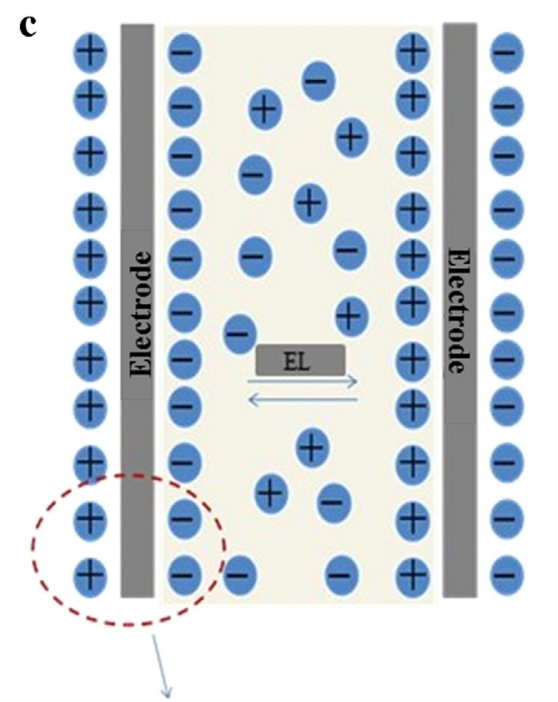

Electric double layer

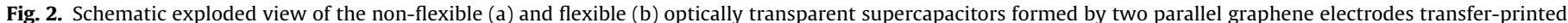
on glass (a) or PVC (b) substrates and the electrolyte medium between them; schematic drawing of behavior of the supercapacitor (c).

Table 1

Electrolytes for graphene-based supercapacitor.

\begin{tabular}{|c|c|c|c|c|}
\hline $\mathrm{N}$ & Type of EL & Ratio & Voltage (V) & Modulation (\%) \\
\hline 1 & PC/LiBOB & $1 / 1.1$ & $0-2.0$ & 1.0 \\
\hline 2 & $\overline{\mathrm{PVA} / \mathrm{H}_{3} \mathrm{PO}_{4}}$ & $1 / 1.5$ & 0 to $-3.0 / 0$ to 3.0 & $1.6 / 1.8$ \\
\hline 3 & $\mathrm{PVA} / \mathrm{H}_{2} \mathrm{SO}_{4}$ & $1 / 1.5$ & 0 to $-3.0 / 0$ to 3.0 & $2.3 / 2.5$ \\
\hline 4 & PVA/LiBOB & $3 / 1$ & 0 to $-2.8 / 0$ to 2.8 & $0.4 / 2.9$ \\
\hline 5 & $\overline{\mathrm{PVA} / \mathrm{LiBOB} / \mathrm{Eth} / \mathrm{Ac}}$ & $1 / 1$ & 0 to $-2.4 / 0$ to 3.0 & $2.7 / 3.2$ \\
\hline 6 & PEO & - & 0 to $-3.0 / 0$ to 3.0 & $1.0 / 2.3$ \\
\hline 7 & PVDF in acetone/ionic liquid & $1 / 4$ & 0 to 2.8 & 3.2 \\
\hline 8 & PVDF in acetonitrile/ionic liquid & $1 / 4$ & 0 to $-2.8 / 0$ to 3.0 & $1.3 / 1.5$ \\
\hline 9 & PVDF/PEO & $9 / 1$ & 0 to $-3.5 / 0$ to 3.0 & $2.3 / 1.3$ \\
\hline
\end{tabular}

*Liquid (1), gel (2-6) and solid electrolyte (7-9). 


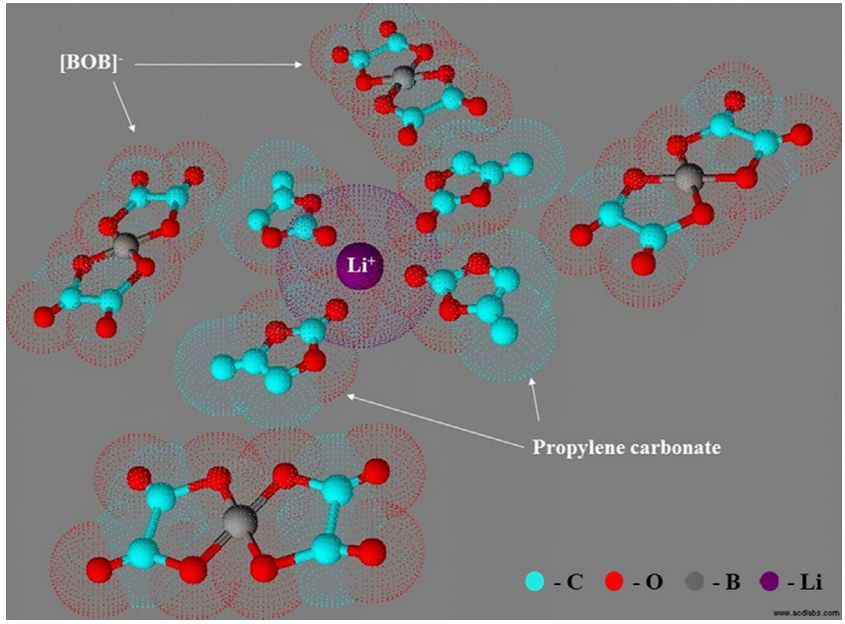

Fig. 3. Schematic behavior between propylene carbonate and lithium bis (oxalate) borate: lithium cation finds itself surrounded by negatively charged oxygen atoms of propylene carbonate; $[\mathrm{BOB}]^{-}$anions are located in the electrolyte solution, thereby determining its mobility.

and good charging/discharging cycles [41], wide electrochemical stability window, no erosion to manganese and iron's cathode materials, fluorine-free, non-toxic, etc. Furthermore, LiBOB has weakest coordinating ability (in comparison with commonly used $\mathrm{LiPF}_{6}$ [42]), can effectively stabilize the graphite anode surface even in pure PC-based electrolytes, and can tolerate as high as about $100 \mathrm{ppm}$ water content $[43,44]$. Aprotic PC has a high molecular dipole moment (4.9 D, due to this we were able to obtain solutions with variety salts concentration) and excellent performance at low temperatures. High polarity propylene carbonate allows to create an effective solvation shell around lithium cations (Fig. 3), thereby obtaining a conductive electrolyte. Accordingly, the mobility of electrolyte will determine the $[\mathrm{BOB}]^{-}$anions.

Electrical characterization of a supercapacitor with $\mathrm{PC} / \mathrm{LiBOB}$ electrolyte shows proportional voltage dependence of capacitance/resistance (Fig. 4a). The capacitance-voltage curve indicates higher capacitance of the device around $40 \mu \mathrm{F} / \mathrm{cm}^{2}$ and minimal point at $-0.34 \mathrm{~V}$. The minimum value of the capacitance corresponds the charge neutrality points of graphene electrodes and depends on the residual charge density. While the almost asymmetric voltage dependence of the resistance represents two distinct peaks at 9.4 and $12.7 \mathrm{k} \Omega$. The total resistance of device varied from 13 to $5.5 \mathrm{k} \Omega$ as a bias voltage change from -4.4 to $4.5 \mathrm{~V}$.

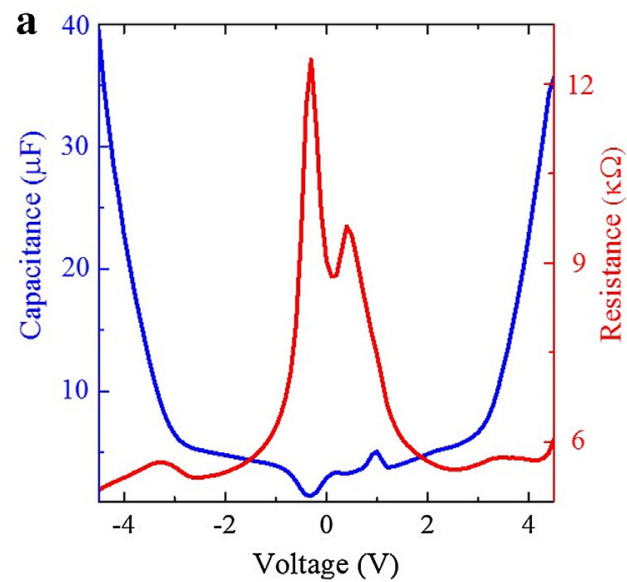

Afterward we investigated electro-optical response of the supercapacitor (Fig. 4b) and noticed symmetrically shift in the transmission around $1 \%$ in the positive and negative voltage ranges. That indicates the destructive effect on graphene by electrostatic doping [45], or more likely modulation of one electrode, due to 1.5-2.0\% optical adsorption of each graphene electrode in the visible and near-IR regimes [39]; however the transmission condition is normalized at $0 \mathrm{~V}$ that confirms a stability of supercapacitor.

Certainly, we have challenges during measurements such as leakage of electrolyte and its drying out under air. Anyway, a high ionic conductivity of liquid electrolyte appears and can be caused by unusual phase transitions at moderate temperatures. Moreover, we were able to expand the boundaries of temperature corridor and apply non-aqueous PC/LiBOB electrolyte for microwave frequency investigations.

\subsection{Gel electrolyte - PVA/LiBOB}

Whereas existing a problem of liquid electrolyte leakage we propose to use polymer-based gel electrolyte. Obvious, that gel plays the role of a container which holds solvent and, as a result, possesses the characteristics of both - liquids and solids.

The addition of LiBOB into polyvinyl alcohol (PVA) increases the amorphousness of the electrolyte [46]. It happens due to the interaction of $\mathrm{Li}^{+}$cation of salt with the oxygen atom of the hydroxyl group in PVA (Fig. 5). The PVA is able to solvate a large amount of salt and provides a reasonably high conductivity. Owing to the decomposition temperature of PVA $\left(230^{\circ} \mathrm{C}\right)$ and LiBOB $\left(>290^{\circ} \mathrm{C}\right)$ the electrolyte can be more stable in a broad temperature range.

The electrical characterization of a supercapacitor with PVA/LiBOB shows symmetric voltage dependence of capacitance/resistance curves (Fig. 6a) with a bias voltage change from -2.0 to $1.0 \mathrm{~V}$. This occurs due to the interaction between more active ions $\left(\mathrm{Li}^{+}\right)$and graphene surface. The graphene electrodes are neutrality at $-1.2 \mathrm{~V}$ that confirmed by one minimum on a capacitance-voltage curve. The higher capacitance of the device observes at $78 \mu \mathrm{F} / \mathrm{cm}^{2}$. Analysis of the resistance-voltage curve (in mode from 7.5 to $12 \mathrm{k} \Omega$ ) shows emerging of the sole peak at $12 \mathrm{k} \Omega$.

The electro-optical test detects the gradual growing in the transmission at 3 and $0.4 \%$, during a variety of the voltage between 0 to $+2.8 \mathrm{~V}$ and -2.8 to $0 \mathrm{~V}$, respectively (Fig. $6 \mathrm{~b}$ ). Thereby, the supercapacitor is active in opposite directions due to reactivity of both ions $\left(\mathrm{Li}^{+}\right.$and $\left.\mathrm{BOB}^{-}\right)$in the dependence on supplied voltage. The modulation of each electrode is negligible with a wavelength from 600 to $1100 \mathrm{~nm}$ and it normalizes at $0 \mathrm{~V}$.

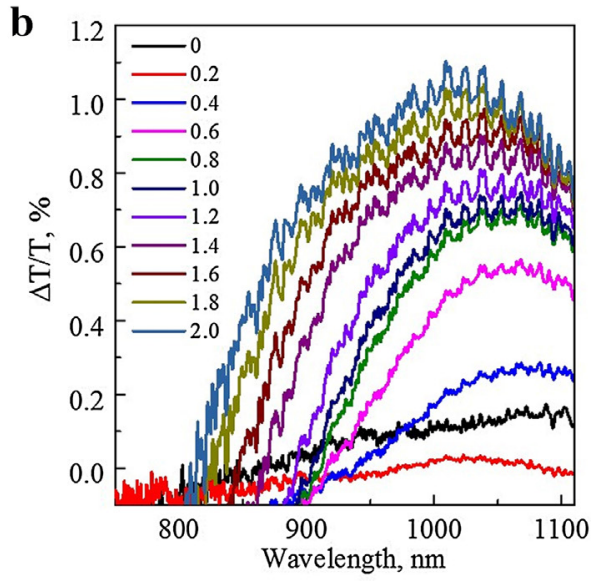

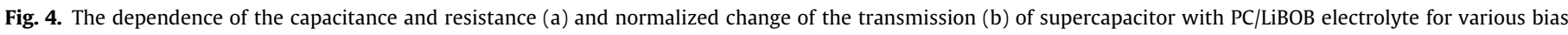
voltages. 


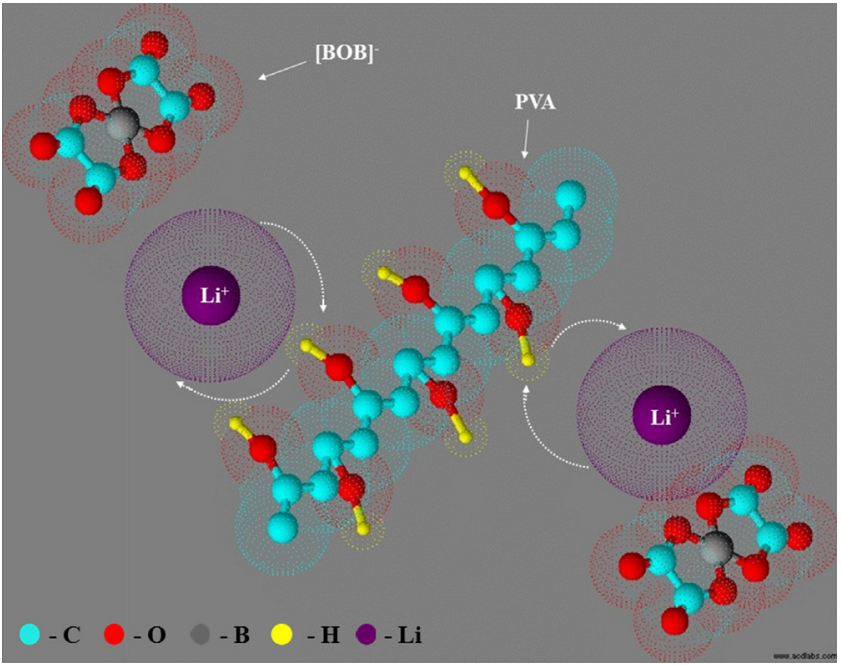

Fig. 5. Schematic interaction between lithium bis (oxalate) borate and polyvinyl alcohol via interaction of lithium cations of salt with the oxygen atoms of the hydroxyl group in PVA.

Thus, we achieved conduction which provides by free mobile lithium cations and obtained following benefits: the polymer matrix provides mechanical stability and helps to avoid the leakage and drying problems of electrolyte; the solvent acts as a conducting medium; the supercapacitor with PVA/LiBOB electrolyte is suitable for visible and near-IR frequency investigations in opposite regions.

\subsection{Solid electrolyte - PVDF/ionic liquid}

To avoid challenges of liquid and gel electrolytes, during supercapacitor fabrication and its testing, we propose solid electrolyte polyvinylidene fluoride (PVDF) with ionic liquid (Fig. 7). It is a perfect combination for the purpose of the fabrication solid-state and flexible device.

The PVDF matrix is promising and suitable polymer due to its high dielectric constant $(11.38 \mathrm{D})$, low crystallinity and low glass transition temperature [47-49]. The (VDF)-phase makes polymer chemically stable and plastically [50], the strong electronwithdrawing functional groups $(-\mathrm{C}-\mathrm{F})$ - highly anodically stable [25].

As a doping agent, we use ionic liquid (1-butyl-3methylimidazolium hexafluorophosphate), which have been recognized as an ideal candidate to substitute the traditional

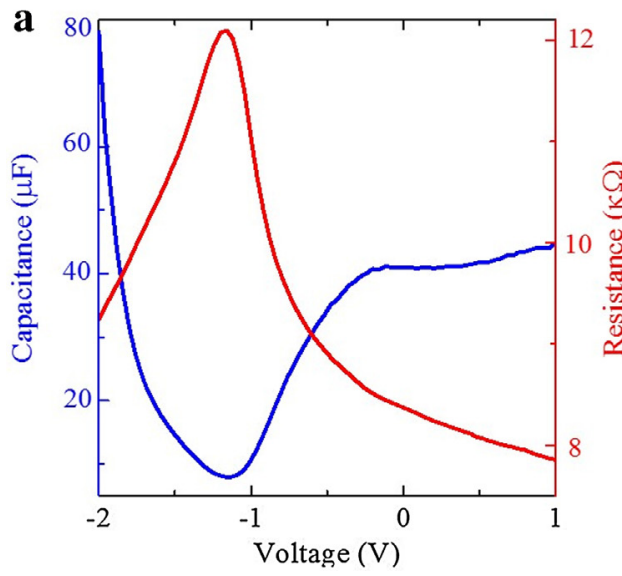

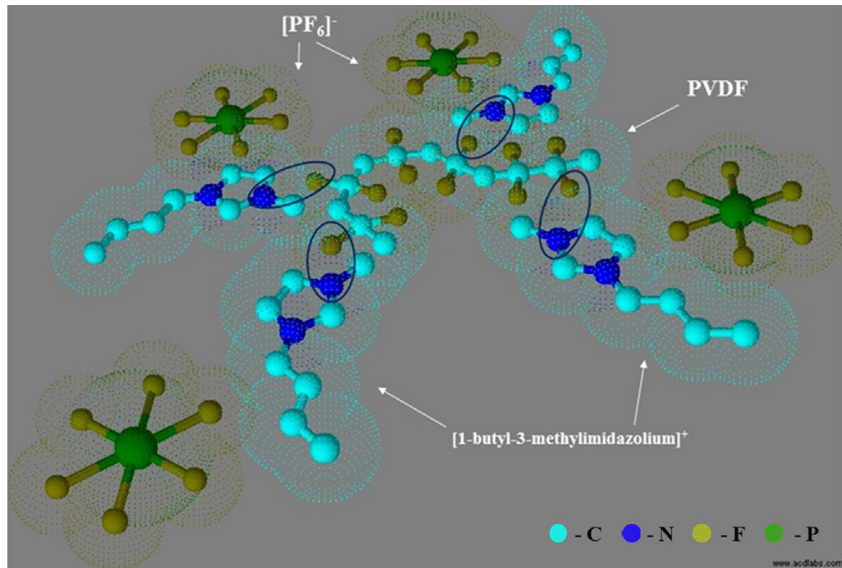

Fig. 7. Schematic molecular structure and proton hopping mechanism between polyvinylidene fluoride and 1-butyl-3-methylimidazolium hexafluorophosphate.

electrolytes. It possesses unique properties: low vapor pressure, non-flammability, excellent electrochemical/thermal stability and unlike aqueous electrolytes has wider electrochemical windows $(>1 \mathrm{~V})[51]$.

The profound dependence of capacitance/resistance of supercapacitor with PVDF/ionic liquid electrolyte demonstrates higher capacitance of a device at $15.5 \mu \mathrm{F} / \mathrm{cm}^{2}$ and total resistance varied from 4.5 to $13.5 \mathrm{k} \Omega$. (Fig. 8a). Applying voltage from -3 to $3 \mathrm{~V}$, we obtain two clearly neutrality charged points of graphene electrodes on the capacitance-voltage curve $(-0.5$ and $0.5 \mathrm{~V})$ and two adjacent peaks ( 13 and $11 \mathrm{k} \Omega$ ) on the resistance-voltage curve.

Then optical transmission shift (from 500 to $1100 \mathrm{~nm}$ ) appears in a positive region from 0 to $2.8 \mathrm{~V}$ (Fig. $8 \mathrm{~b}$ ). These are symmetrically changes in $3.2 \%$ that indicate a modulation of two electrodes; the transmission condition of supercapacitor normalized at $0 \mathrm{~V}$.

Thus, doping of polymer with ionic liquid is a good approach to develop electrolyte in the film form. Namely, the nonpolar nature of the PVDF provides structural integrity and, at the same time, forms high ionically conductive channels, offering its suitability as an electrolyte in supercapacitors.

\section{Conclusions}

In summary, we report electro-optical features of a graphenebased optical modulator with supercapacitor structure using liquid, gel, and solid electrolytes. We established the best capacitance at

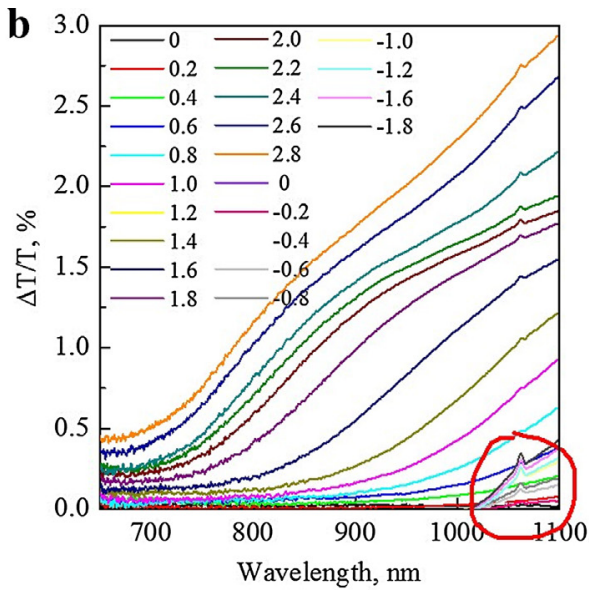

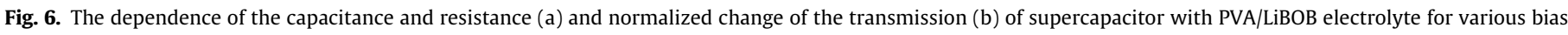
voltages. 

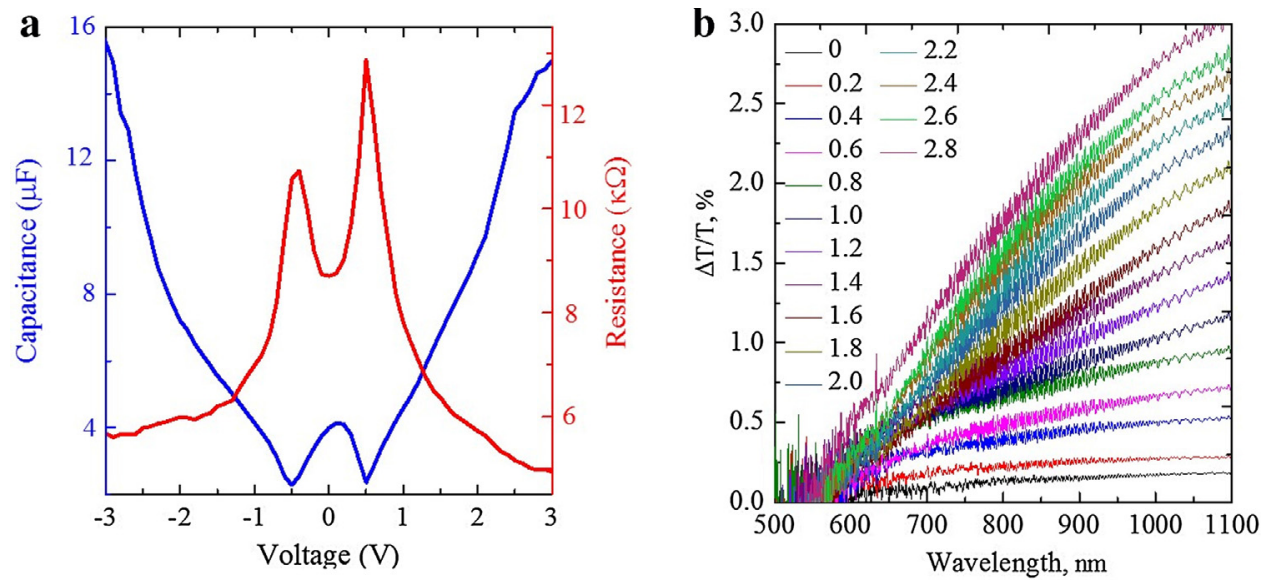

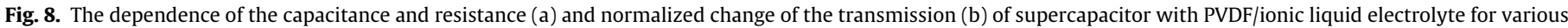
bias voltages.

$78 \mu \mathrm{F} / \mathrm{cm}^{2}$ for gel PVA/LiBOB electrolyte and showed its possibility to operate in two directions as well, due to the simultaneous activity of $\mathrm{Li}^{+}$and [BOB] ions. We demonstrated capacitance at $15.5 \mu \mathrm{F} / \mathrm{cm}^{2}$ and increasing of light transmission in 3 times for solid PVDF/ionic liquid electrolyte. We noted following challenges: leakage/drying under an air of liquid $\mathrm{PC} / \mathrm{LiBOB}$ electrolyte, impossibilities of using of aqueous gel PVA/LiBOB electrolyte in microwave frequency investigation. Therefore, we would like to distinguish most suitable electrolyte for graphene-based supercapacitors solid PVDF/ionic liquid electrolyte with satisfactory electro-optical results, chemical/thermal stability, and flexibility.

We anticipate that application of the proposed electrolytes together with simplicity and variety of the graphene-based device geometry will enable a variety of advanced optical devices ranging from plasmonics to optoelectronics. Graphene supercapacitor can be used as a saturable absorber due to graphene ultrawide broadband capability and lower saturation intensity. A novel supercapacitor with transparent graphene electrodes fabricated on flexible substrate could apply as electrically reconfigurable flexible coatings or smart windows as well.

\section{Acknowledgement}

This work was supported by the Scientific and Technological Research Council of Turkey (TUBITAK) grant no. 114F052 and $113 \mathrm{~F} 278$.

\section{References}

[1] J. Energy Eng. 139 (2013) 72-79.

[2] G. Wang, L. Zhang, J. Zhang, Chem. Soc. Rev. 41 (2012) 797-828.

[3] H. Shen, E. Liu, X. Xiang, Z. Huang, Y. Tian, Y. Wu, Z. Wu, H. Xie, Mater. Res. Bull. 47 (2012) 662-666.

[4] M.D. Stoller, S. Park, Y. Zhu, J. An, R.S. Ruoff, Nano Lett. 8 (2008) 3498-3502.

[5] L.L. Zhang, R. Zhou, X.S. Zhao, J. Mater. Chem. 20 (2010) 5983-5992.

[6] J. Zou, J. Liu, A.S. Karakoti, A. Kumar, D. Joung, Q. Li, S.I. Khondaker, S. Seal, L. Zhai, ACS Nano 4 (2010) 7293-7302.

[7] H. Hu, Z. Zhao, W. Wan, Y. Gogotsi, J. Oiu, Adv. Mater. 25 (2013) 2219-2223.

[8] A. Izadi-Najafabadi, S. Yasuda, K. Kobashi, T. Yamada, D.N. Futaba, H. Hatori, M. Yumura, S. Iijima, K. Hata, Adv. Mater. 22 (2010) E235-E241.

[9] M. Kaempgen, C.K. Chan, J. Ma, Y. Cui, G. Gruner, Nano Lett. 9 (2009) $1872-1876$.

[10] G. Yu, L. Hu, M. Vosgueritchian, H. Wang, X. Xie, J.R. McDonough, X. Cui, Y. Cui, Z. Bao, Nano Lett. 11 (2011) 2905-2911.

[11] B.J. Lee, S.R. Sivakkumar, J.M. Ko, J.H. Kim, S.M. Jo, D.Y. Kim, J. Power Sources 168 (2007) 546-552.

[12] Z. Ruifeng, M. Chuizhou, Z. Feng, L. Qunqing, L. Changhong, F. Shoushan, J. Kaili, Nanotechnology 21 (2010) 345701.

[13] W. Tang, L. Liu, S. Tian, L. Li, Y. Yue, Y. Wu, K. Zhu, Chem. Commun. 47 (2011) 10058-10060.

[14] H.-H. Chang, C.-K. Chang, Y.-C. Tsai, C.-S. Liao, Carbon 50 (2012) 2331-2336.
[15] Y.-Y. Horng, Y.-C. Lu, Y.-K. Hsu, C.-C. Chen, L.-C. Chen, K.-H. Chen, J. Power Sources 195 (2010) 4418-4422.

[16] M. Mastragostino, C. Arbizzani, F. Soavi, J. Power Sources 97-98 (2001) $812-815$.

[17] V. Di Noto, S. Lavina, G.A. Giffin, E. Negro, B. Scrosati, Electrochim. Acta 57 (2011) 4-13.

[18] B.E. Conway, W.G. Pell, J. Solid State Electrochem. 7 (2003) 637-644.

[19] A.G. Pandolfo, A.F. Hollenkamp, J. Power Sources 157 (2006) 11-27.

[20] M. Frank Rose, C. Johnson, T. Owens, B. Stephens, J. Power Sources 47 (1994) 303-312.

[21] W. Xu, C.A. Angell, Electrochem. Solid State Lett. 4 (2001) E1-E4.

[22] M.D. Glasse, R. Idris, R.J. Latham, R.G. Linford, W.S. Schlindwein, Solid State Ionics 147 (2002) 289-294.

[23] J. Maranas, Solid polymer electrolytes, in: V. García Sakai, C. Alba-Simionesco, S.-H. Chen (Eds.), Dynamics of Soft Matter, Springer, US, 2012, pp. 123-143.

[24] A. Manuel Stephan, Eur. Polym. J. 42 (2006) 21-42.

[25] J.Y. Song, Y.Y. Wang, C.C. Wan, J. Power Sources 77 (1999) 183-197.

[26] G. Feuillade, P. Perche, J. Appl. Electrochem. 5 (1975) 63-69.

[27] S. Ramesh, K.H. Leen, K. Kumutha, A.K. Arof, Spectrochim. Acta A 66 (2007) 1237-1242.

[28] F.J. Baltá Calleja, A.G. Arche, T.A. Ezquerra, C.S. Cruz, F. Batallán, B. Frick, E.L. Cabarcos, Structure and properties of ferroelectric copolymers of poly(vinylidene fluoride), in: H.G. Zachmann (Ed.), Structure in Polymers with Special Properties, Springer Berlin Heidelberg, 1993, pp. 1-48.

[29] C. Meng, C. Liu, L. Chen, C. Hu, S. Fan, Nano Lett. 10 (2010) 4025-4031.

[30] C. Meng, C. Liu, S. Fan, Electrochem. Commun. 11 (2009) 186-189.

[31] J.J. Yoo, K. Balakrishnan, J. Huang, V. Meunier, B.G. Sumpter, A. Srivastava, M. Conway, A.L. Mohana Reddy, J. Yu, R. Vajtai, P.M. Ajayan, Nano Lett. 11 (2011) $1423-1427$.

[32] K. Yu Jin, C. Haegeun, H. Chi-Hwan, K. Woong, Nanotechnology 23 (2012) 065401.

[33] X. Li, W. Cai, J. An, S. Kim, J. Nah, D. Yang, R. Piner, A. Velamakanni, I. Jung, E Tutuc, S.K. Banerjee, L. Colombo, R.S. Ruoff, Science 324 (2009) 1312-1314.

[34] E.O. Polat, O. Balci, N. Kakenov, H.B. Uzlu, C. Kocabas, R. Dahiya, Sci. Rep. 5 (2015) 16744

[35] B. Jalali, S. Fathpour, J. Lightwave Technol. 24 (2006) 4600-4615.

[36] D.A.B. Miller, Opt. Express 20 (2012) A293-A308.

[37] S.J. Koester, M. Li, Appl. Phys. Lett. 100 (2012) 171107.

[38] M. Liu, X. Yin, X. Zhang, Nano Lett. 12 (2012) 1482-1485.

[39] E.O. Polat, C. Kocabas, Nano Lett. 13 (2013) 5851-5857.

[40] Wu Xu, C. Austen Angellz, Electrochem. Solid-State Lett. 4 (2001) E1-E4.

[41] S. Wang, W. Qiu, T. Li, B. Yu, H. Zhao, Int. J. Electrochem. Sci. 1 (2006) 250-257.

[42] K. Xu, S. Zhang, T.R. Jow, W. Xu, C.A. Angell, Electrochem. Solid State Lett. 5 (2002) A26-A29.

[43] L. Yang, M.M. Furczon, A. Xiao, B.L. Lucht, Z. Zhang, D.P. Abraham, J. Power Sources 195 (2010) 1698-1705.

[44] K. Xu, S. Zhang, B.A. Poese, T.R. Jow, Electrochem. Solid State Lett. 5 (2002) A259-A262.

[45] Y.V. Pleskov, Russ. J. Electrochem. 37 (2001) 871-872.

[46] I.S. Noor, S.R. Majid, A.K. Arof, Electrochim. Acta 102 (2013) 149-160.

[47] F. Wu, T. Feng, Y. Bai, C. Wu, L. Ye, Z. Feng, Solid State Ionics 180 (2009) $677-680$.

[48] H. Xie, Z. Tang, Z. Li, Y. He, Y. Liu, H. Wang, J. Solid State Electrochem. 12 (2008) 1497-1502.

[49] S. Ramesh, O.P. Ling, Polym. Chem. 1 (2010) 702-707.

[50] M. Ulaganathan, S. Rajendran, J. Appl. Polym. Sci. 118 (2010) 646-651.

[51] T. Abdallah, D. Lemordant, B. Claude-Montigny, J. Power Sources 201 (2012) 353-359. 